\title{
Gamification of dermatology: Stud2yBuddy, a novel game to facilitate dermatology revision for final-year medical students
}

\author{
Authors: Rachel Ventre, Cleone Pardoe, Shabnam Singhal, David Cripps and Josephine Hough
}

\section{Introduction}

Medical students are subject to high levels of stress and anxiety during revision and assessment periods. ${ }^{1}$ Literature supports game-based learning in higher education, improving motivation to learn and interactive peer assessment. ' 'Serious games' have a pedagogical design. ${ }^{3}$ Games can help to develop analytical skills and increase retention through active learning. Also, compared with traditional pedagogical methods, educational games result in less stress and anxiety. ${ }^{4,5}$ Games in education additionally help to promote team building and develop professional skills, offering an alternative method to teaching these valuable skills. ${ }^{3}$

We present the board game Stud2yBuddy, a novel approach to facilitating dermatology revision.

Our aim was to develop an effective interactive resource to improve confidence in dermatology and encourage peer feedback and self-assessment in finals revision.

\section{Methods}

We identified through questionnaire responses that students find dermatology difficult and stressful to learn; gamification of dermatology could overcome this. We designed a card-based board game with four categories, incorporating different learning styles. Learning outcomes were blueprinted against a British university medical school curriculum. A prototype board game was trialled with junior and senior medical educators, and subsequent feedback and quality assurance resulted in further game development.

Final-year medical students $(n=65)$ attended facilitated revision workshops featuring the Stud2yBuddy board game, in addition to a traditional pedagogical lecture. Quantitative and qualitative data assessing learning styles and confidence in dermatology were collected before and after the session using Likert response questionnaires and open-ended questions.

\section{Results and discussion}

Likert responses showed an increase in mean confidence levels from pre-session to post-session across various aspects of dermatology (mean \pm standard deviation): diagnosis $3.26 \pm 0.70$ to $3.88 \pm 0.57$

Authors: South Warwickshire NHS Foundation Trust, Warwickshire, UK
( $p<0.001)$, investigation $3.02 \pm 0.72$ to $3.47 \pm 0.64(p<0.001)$, management $3.25 \pm 0.72$ to $3.52 \pm 0.61$ ( $p=0.016)$, recognition of dermatological lesions $3.07 \pm 0.74$ to $3.97 \pm 0.55$ ( $p<0.001$ ), description of describing dermatological lesions $2.98 \pm 0.86$ to $3.82 \pm 0.58(p<0.001)$.

Students agreed that gameplay was interactive (100\%), motivational (97\%), achieved learning goals ( $80 \%)$, identified weaknesses (88\%), incorporated sufficient feedback (91\%), facilitated learning through teamwork (91\%) and was less stressful than traditional methods of teaching ( $86 \%$ ). Qualitative themes included group participation, variation of topics and learning styles, knowledge application and enjoyment.

\section{Conclusion}

The Stud2yBuddy board game gamifies dermatology to create an interactive learning and revision resource. The game incorporates peer feedback and self-assessment which students found beneficial for learning, and it increases confidence in revising dermatology. Our game is enjoyable and less stressful than other revision methods; this is in line with current research into game-based learning.

Novel revision methods such as board games provide a wealth of opportunity for improving student engagement, reducing stress and anxiety while improving content understanding. Further evaluation into the efficacy of educational impact is an exciting area to be explored. This is easily applicable to other medical specialties and could be developed as a revision tool for specialty examinations.

\section{References}

1 Lyndon MP, Strom JM, Alyami HM et al. The relationship between academic assessment and psychological distress among medical students: a systematic review. Perspect Med Educ 2014;3:405-18.

2 Bigdeli S, Kaufman D. Digital games in medical education: key terms, concepts, and definitions. Med J Islam Repub Iran 2017:31:52.

3 Gorbanev I, Agudelo-Londoño S, González RA et al. A systematic review of serious games in medical education: quality of evidence and pedagogical strategy. Med Educ Online 2018;23:1438718.

4 Akl EA, Gunukula S, Mustafa R et al. Support for and aspects of use of educational games in family medicine and internal medicine residency programs in the US: a survey. BMC Med Educ 2010;10:26.

5 Begg M. Leveraging game-informed healthcare education. Med Teach 2008:30:155-8. 